\title{
THE TERM STRUCTURE AS A PREDICTOR OF RECESSIONS
}

\author{
E Moolman*
}

\begin{abstract}
$\mathrm{D}_{\mathrm{b}}$ espite the existence of macroeconomic models and complex business cycle indicators, policymakers and market participants can benefit by looking at a few well-chosen indicators such as the term structure of interest rates in predicting business cycle turning points. If the term structure accurately predicts business cycle turning points, it provides an easy way to confirm the predictions of macroeconomic models, or it can eliminate the need for a macroeconomic model the interest is in the turning points and not in the levels of the business cycle. The objective of this paper is to predict turning points of the South African business cycle based on its relationship with the term structure of interest rates. A probit model was used, and the results indicate that the term structure successfully predicts turning points of business cycle two quarters ahead. The negative empirical relationship between the term structure of interest rates and the business cycle conforms to economic theory.
\end{abstract}

\section{Introduction}

The modern literature on business cycles dates back to the seminal work of Burns and Mitchell (1946). They defined the business cycle as follows: "a cycle consists of expansions occurring at about the same time in many economic activities, followed by similarly general recessions, contractions and revivals that merge into the expansion phase of the next cycle: this sequence of change is recurrent but not periodic" (Burns and Mitchell, 1946:3). This definition remains the basis of business cycle analysis, and specifically, it is the foundation of several recent studies that model the characteristics that distinguish expansions from contractions.

This study will model the two features of the Burns and Mitchell definition, namely the occurrence of expansions and contractions, and the common movements of each of the two phases. Specifically, the relationship between the phases of the business cycle and the term structure of interest rates will be modelled, and this relationship will be used to predict the business cycle turning points.

Despite the existence of macroeconomic models and composite indexes of leading business cycle indicators, policymakers and market participants can benefit in

*Department of Economics, University of Pretoria, Pretoria 0002, Republic of South Africa.

Email address: emoolman@hakuna.up.ac.za 
several ways by looking at a few well-chosen indicators such as the term structure of interest rates in predicting business cycle turning points. Accurate predictions of business cycle turning points will assist policy-makers in understanding the lag with which monetary policy affects the real economy, investors can improve profits by knowing when asset prices will reach a maximum or minimum (based on the relationship between the asset and the business cycle), and producers can improved their inventory planning. If the yield spread accurately predicts business cycle turning points, it provides a quick and easy way to confirm the predictions of macroeconomic models, or if the economic agent is only interested in the turning point and not the level of the business cycle he doesn't need a macroeconomic model but can simply look at the yield spread. The objective of this paper is to predict turning points of the South African business cycle based on its relationship with the term structure of interest rates, not to model or predict the levels of the business cycle.

The study is organized as follows: the next section explains the theory behind the relationship between the yield spread and the business cycle. Section 3 gives the literature review, and Section 4 describes the model used. Section 5 presents the results of the empirical analysis, while Section 6 provides the conclusion.

\section{Theory}

There are two explanations for relationship between the term structure of interest rates or the yield spread between similar short-term and long-term interest rates (the so-called "yield spread") and the business cycle. For the first explanation, assume that the country is currently enjoying high growth, so that there is a general agreement among investors that the country is heading for a slow-down or recession in the future. Consumers want to hedge against the recession, and therefore purchase financial instruments (e.g. long-term bonds) that will deliver pay-offs during the economic slowdown. The increased demand for long-term bonds causes an increase in the price of long-term bonds, in other words a decrease in the yield on long-term bonds. In order to finance these purchases, investors sell their shorter-term assets, which results in a decline in the price of short-term assets, and an increase in the yield on short-term assets. In other words, if a recession is expected, long-term interest rates will fall and short-term interest rates will rise. Consequently, prior to the recession, the slope of the term structure of interest rates will become flat or inverted, which means that the yield spread declines. Similarly, long-term interest rates rises while short-term interest rates falls when an expansion is expected, so that an upward-sloping yield curve predicts an expansion.

The second explanation is based on the expectations hypothesis of the term structure of interest rates. This hypothesis is based on the assumption that similar financial instruments with different maturities are perfect substitutes, so that an investor will be indifferent between investing in one long-term instrument or several similar consecutive short-term instruments as long as their expected returns are equal (Mishkin, 1998:156). This means that, for similar financial instruments, the long-term yield will be the average of current and future short-term yields. Assume that a central bank tightens monetary policy by raising short-term rates. 
Economic agents will view this as a temporary shock, and therefore they expect future short-term rates to rise by less than the current change in short-term interest rates. Based on the expectations hypothesis of the term structure, long-term rates will rise by less than the current short rate. This will lead to a flatter or even an inverted yield curve. Since monetary policy affects economic activity with a lag of one to two years, the tightening of policy will cause a reduction of future economic activity and an increase in the probability of a recession. Therefore, prior to a recession (expansion), the yield spread will decline (increase).

\section{Literature review}

The first empirical analysis of the term structure as predictor of real economic activity was done by Estrella and Hardouvelis (1991). Their study was based on quarterly data for the US for the period 1955 to 1988 . Regressions of future GNP growth on the slope of the yield curve and other information variables showed that a steeper (flatter) slope implies faster (slower) future growth in real output. The estimated constant and coefficient of the yield spread for GNP one to five quarters ahead are approximately 1.70 and 1.30 respectively. The positive constant term implies that a negative slope does not necessarily predict negative future real GNP growth. They used a probit model to analyze the predictive power of the term structure on a binary variable that simply indicates the presence or absence of a recession. The probit model relates the probability of a recession as dated by the NBER during the current quarter to the slope of the yield curve lagged four quarters. Their results showed that the probability of a recession this quarter is a negative function of the slope of the yield curve lagged four quarters, in other words, an increase in the spread between the long- and short-term interest rates implies a decrease in the probability of a recession 4 quarters later.

Ivanona, Lahiri, Seitz (2000) compared the performance of a number of interest rate spreads as predictors of the German business cycle. They use five different interest rate spreads: the spread between 1-2 year and 9-10 year government bonds, the spread between 1-2 year and 9-10 year bank bonds, the spread between 1-2 year bank bonds and 1-2 year government bonds, the spread between the Lombard rate and 9-10 year government bonds, and the spread between the call rate and 9-10 year government bonds. Their results indicate that the yield spread leads the business cycle peak by four months. The bank spreads perform better than the public spreads in predicting recessions, and neither of them gives any false signals. However, the spread between 1-2 year government and bank bonds gives multiple false signals. The call rate spread performs slightly inferior, since its predictions lag the predictions of the other spreads.

Bernard and Gerlach (1996) tested the ability of both the domestic and foreign term structures to predict business cycle turning points in eight countries for the period 1972:1 to 1993:4 with probit models. The domestic term spreads are statistically significant in explaining business cycle turning points in all eight countries. The period over which the domestic term spread successfully forecast the turning points vary across countries, but the optimal forecast period range from two to five 
quarters. In general, downward-sloping (upward-sloping) yield curves have historically been associated with subsequent recessions (expansions).

Estrella and Mishkin (1998) compared the performance of various financial variables, including four term structures of interest rates, stock prices, monetary aggregates, indexes of leading indicators and other economic variables such as GDP, CPI and exchange rates, as predictors of US recessions. They estimated probit models with quarterly data for the period 1959 to 1995 . Their results indicated that the yield curve outperforms the other indicators for forecasting beyond one quarter ahead.

The only study on the relationship between the term structure of interest rates and the business cycle in the South Africa economy was done by Nel (1996). Unlike the other studies, he analyzed the contemporaneous relationship with cointegration techniques, instead of the lead-lag relationship dictated by theory. He showed that quarterly real GDP is a positive function of the yield spread between 10-year government bonds and the three month banker's acceptance rate. He found real GDP and the yield spread to be cointegrated, and showed that the yield spread is statistically significant in explaining GDP, despite a poor overall fit. Nel (1996) modeled the level or course of the business cycle, while this study will focus on predicting only turning points.

\section{The model}

Several authors used probit models to study the ability of the term structure to predict business cycle turning points (see e.g. Estrella and Hardouvelis, 1991; Dueker, 1997; Dotsey, 1998; Estrella and Mishkin, 1998; Bernard and Gerlach, 1996). The probit form is dictated by the fact that the variable being predicted takes on only two possible values - whether the economy is in a recession or not. The model is defined in reference to a theoretical linear relationship of the form:

$\mathrm{Y}_{\mathrm{t}+\mathrm{k}}^{*}=\alpha+\beta * \mathrm{x}_{\mathrm{t}}+\varepsilon_{\mathrm{t}}$

where $\mathrm{Y}_{\mathrm{t}}^{*}$ is an unobservable that determines the occurrence of a recession at time $\mathrm{t}, \mathrm{k}$ is the length of the forecast horizon, $\varepsilon_{\mathrm{t}}$ is a normally distributed error term, and $x_{t}$ the slope of the yield curve (or yield spread) at time t. The parameters $\alpha$ and $\beta$ are estimated with maximum likelihood. The observable recession indicator $R_{t}$, defined as the times that the Reserve Bank officially categorized as downswings, is related to this model by

$\mathrm{R}_{\mathrm{t}}=1$ if $\mathrm{Y}_{\mathrm{t}}^{*}>0$, and 0 otherwise

The form of the estimated equation is

$\mathrm{P}\left(\mathrm{R}_{\mathrm{t}+\mathrm{k}}=1\right)=\mathrm{F}\left(\alpha+\beta^{*} \mathrm{x}_{\mathrm{t}}\right)$

where $\mathrm{F}$ is the cumulative normal distribution function.

J.STUD.ECON.ECONOMETRICS, 2002, 26(3) 
The model is estimated by maximum likelihood. The recession indicator is obtained from the South African Reserve Bank, that is,

$\mathrm{R}_{\mathrm{t}}=1$ if the Reserve Bank classified the economy to be in a recession at time $\mathrm{t}$, and 0 otherwise

\section{Empirical analysis}

Quarterly data for the period 1979:1 to 2001:3 was used in the empirical analysis. Following Nel (1996), the yield spread was defined as the yield difference between 10-year government bonds and 3-month banker's acceptances. Unit root tests showed that the quarterly growth rate and the yield spread are stationary (see Appendix). Figure 1 plots the yield spread along with the periods that the SARB classified as official recessions. The shaded areas represent the official recessions, while the line represents the yield spread.

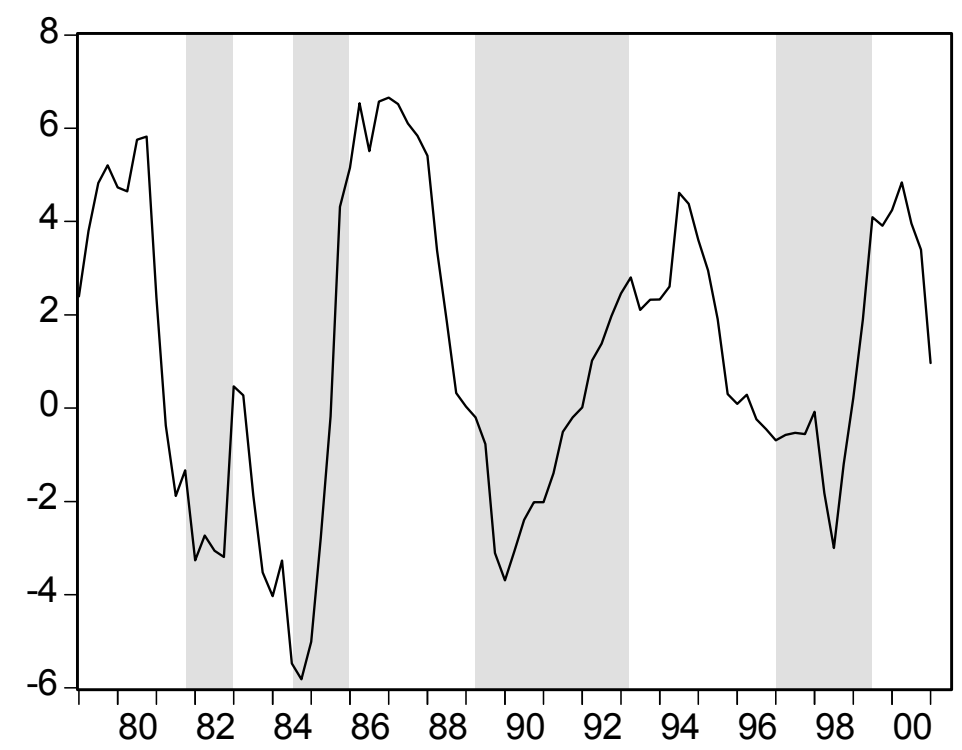

Figure 1: Recessions and the yield spread

The optimal forecast period was determined by estimating probit models with one to six lags, and using the lag that provided the minimum Akaike and SchwartzBayesian and the maximum log likelihood. The results showed that the term structure is best at predicting the state of the business cycle two quarters ahead. Therefore, two lags were used in the probit model and the Granger causality tests.

Granger causality tests were performed to test whether a causal relationship exists between the yield spread and the recession dummy. The results suggest that that there is unidirectional causality from the yield spread to the recession dummy (see 
Table 1). This means that the yield spread significantly improves forecasts of whether the economy will be in a recession.

Table 1: Granger causality tests

\begin{tabular}{||l|c|c||}
\hline \multicolumn{1}{|c|}{ Null hypothesis } & F-statistic & p-value \\
\hline Yield spread does not Granger cause Recession & $12,1382 * * *$ & $2,3 \mathrm{E}-05$ \\
\hline Recession does not Granger cause Yield Spread & 0,51131 & 0,60154 \\
\hline
\end{tabular}

*** Statistically significant at $1 \%$ level

The probit model discussed in Section 2 was used to model the probability that the economy will be in a recession two quarters ahead, based on the current yield spread. The parameters were estimated by maximum likelihood.

Table 2: Probit model

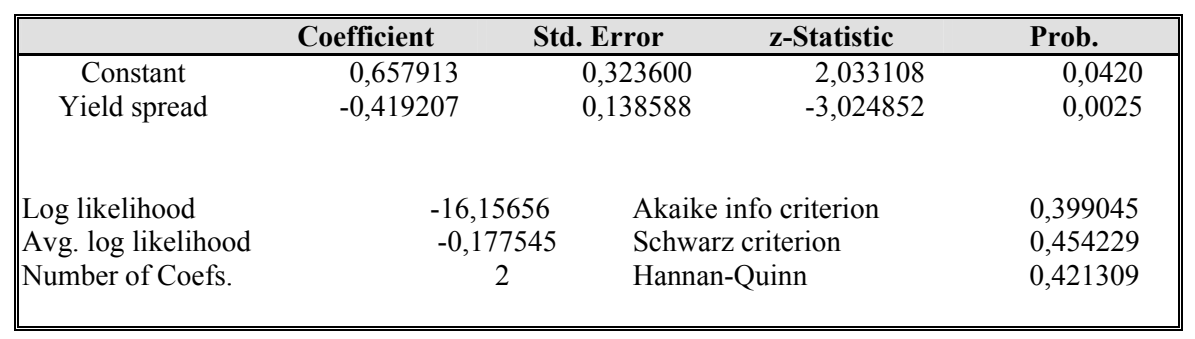

The results in Table 2 indicate that the probability of a recession in a specific quarter is a negative function of the yield lagged spread two quarters, as well a positive constant. Expressed algebraically,

$\mathrm{P}\left(\mathrm{R}_{\mathrm{t}+2}=1\right)=\mathrm{F}\left(0.657913-0.419207 * \mathrm{x}_{\mathrm{t}}\right)$

where $\mathrm{F}$ is the cumulative normal distribution, $\mathrm{x}_{\mathrm{t}}$ is the yield spread in period $\mathrm{t}$, and $\mathrm{R}_{\mathrm{t}}$ is a dummy variable that takes on the values one if the economy is in a recession in period 1 .

In other words, an increase in the spread between the long-term and short-term interest rates implies a decrease in the probability of a recession two quarters later. According to the results in Table 2, the relationship between the probability of a recession and the yield spread is statistically significant.

Figure 2 plots the estimated probability of a recession derived from the historical data on the yield spread lagged two quarters, the parameter estimated in Table 2, 
and the cumulative normal distribution. The shaded areas denote periods of actual recessions as classified by the South African Reserve Bank.

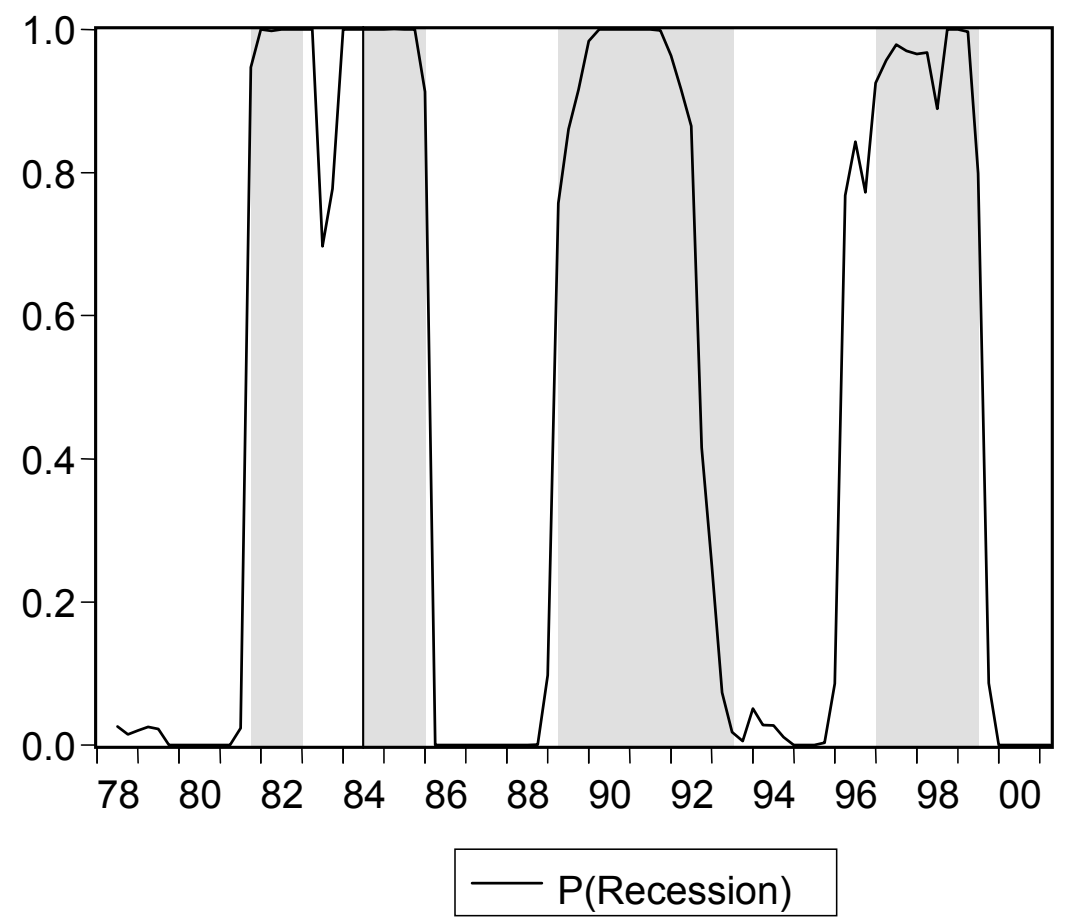

Figure 2: Recessions and estimated probabilities of recessions

In seven of the eight turning points, the peak of the estimated probability of a turning point preceded the actual turning point by zero to two quarters, in other words the yield spread predicted turning points two to four quarters ahead. The only exception was the upswing in April 1983, when the estimated probability of a recession declined but was higher than with the other upswings. This means that, based on a dating rule that classifies recessions (expansions) as estimated probabilities above (below) 50\%, the model missed only the upswing in 1983 . (However, if the dating rule classifies recessions (expansions) as estimated probabilities above (below) 0,7 , the model predicted all the turning points.) If the upswing of 1983 is excluded, the peak of the estimated probability coincided with all the turning points, except for the expansion from June 1993 to November 1996 when it preceded the turning point by 2 quarters. However, this imperfection should be seen in perspective. For most market participants, the cost of expecting the turning point too early is lower than the cost of expecting the turning point too late. A crucial characteristic of this model is that it did not give any false signals. 


\section{Table 3: Probability of a recession two quarters ahead as a function of the}

current yield spread

\begin{tabular}{|c|c|}
\hline Yield spread (\%) & P(recession) \\
\hline-6 & 0,999246 \\
\hline-5 & 0,997056 \\
\hline-4 & 0,990222 \\
\hline-3 & 0,972288 \\
\hline-2 & 0,932716 \\
\hline-1 & 0,859287 \\
\hline 0 & 0,744703 \\
\hline 1 & 0,594333 \\
\hline 2 & 0,428380 \\
\hline 3 & 0,274350 \\
\hline 4 & 0,154122 \\
\hline 5 & 0,075200 \\
\hline 6 & 0,031632 \\
\hline
\end{tabular}

Table 3 gives the probability of a recession two quarters ahead based on the difference between the current yields on 10-year government bonds and the 3month bankers acceptances. For example, if the yield on 10-year government bonds is currently $4 \%$ or more below the yield on 3-month bankers acceptances, the probability that the economy will be in a recession two quarters from now is $99 \%$. On the other hand, if the yield on 10 -year government bonds is currently $4 \%$ above the yield on 3-month bankers acceptances, the probability that the economy will be in a recession two quarters ahead is $15,4 \%$. It is easy to show that a yield spread of $1,5694 \%$ predicts that there is a $50 \%$ probability that the economy will be in a recession two quarters ahead $(1,5694=0.67913 / 0,419207)$. A yield spread greater than $1,5694 \%$ predicts that the economy is more likely to be in a recession than in an expansion two quarters ahead.

\section{Conclusion}

In this study, a probit model was used to evaluate the term structure or yield spread as a predictor of turning points in the South African business cycle. The yield spread was defined as the difference between the yield on 10-year government bonds and 3-month banker's acceptances. The results indicated that the term structure or yield spread successfully predicts turning points of business cycle two quarters ahead. The negative empirical relationship between the term structure of interest rates and the business cycle conforms to economic theory.

If the yield on 10 -year government bonds is currently $4 \%$ or more below the yield on 3-month bankers acceptances, the probability that the economy will be in a recession two quarters ahead is $99 \%$. On the other hand, if the yield on 10-year 
government bonds is currently $4 \%$ above the yield on 3-month bankers acceptances, the probability that the economy will be in a recession two quarters ahead is $15,4 \%$. A yield spread greater than $1,5694 \%$ predicts that the economy is more likely to be in a recession than in an expansion two quarters ahead.

\section{References}

Bernard, H and Gerlach, S (1996): "Does the Term Structure Predict Recession? The International Evidence", Bank for International Settlements Working Paper No 37.

Burns, AF and Mitchell, WC (1946): Measuring Business Cycles, New York: National Bureau of Economic Research.

Dotsey, M (1998): "The Predictive Content of the Interest Rate Term Spread for Future Economic Growth", Federal Reserve Bank of Richmond Economic Quarterly, 84, 31-51.

Dueker, MJ (1997): "Strengthening the Case for the Yield Curve as a Predictor of US Recessions", Federal Reserve Bank of St. Louis Review, 79, 41-51.

Estrella, A and Hardouvelis, GA (1991): "The Term Structure as a Predictor of Real Economic Activity", The Journal of Finance, 46, 555-575.

Estrella, A, and Mishkin, FS (1998): "Predicting U.S. Recessions: Financial Variables as Leading Indicators", The Review of Economics and Statistics, 80, 45-60.

Ivanova, D, Lahiri, K and Seitz, F (2000): "Interest Rate Spreads as Predictors of German Inflation and Business Cycles", International Journal of Forecasting, 16(1), 39-58.

Mishkin, F.S. (1998): The Economics of Money, Banking, and Financial Markets, Addison-Wesley.

Nel, H. (1996): "The Term Structure of Interest Rates and Economic Activity in South Africa", The South African Journal of Economics, 64(3), 161-174. 
APPENDIX Augmented Dickey-Fuller and Phillips-Perron tests for nonstationarity, levels

\begin{tabular}{|l|l|l|l|l|l|}
\hline Series & Model & Lags $^{I}$ & $\tau_{\boldsymbol{v}} \tau_{\mu} \tau$ & $\phi_{3}, \phi_{1}$ & $\boldsymbol{P P}^{2}$ \\
\hline Yield Spread & Trend & 1 & -3.13 & $9.69^{* * *}$ & -2.58 \\
& Constant & 0 & $-3.15 * *$ & $14.70 * * *$ & $-2.59 *$ \\
& None & 1 & $-3.05 * * *$ & & $-2.49 * *$ \\
\hline Economic & Trend & 0 & $-5.17 * * *$ & $13.36^{* * *}$ & $-5.22 * * *$ \\
Growth & Constant & 0 & $-5.19 * * *$ & $26.91 * * *$ & $-5.23 * * *$ \\
& None & 0 & $-4.45^{* * *}$ & & $-4.42^{* * *}$ \\
\hline
\end{tabular}

* $\quad$ Significant at a $10 \%$ level.

** $\quad$ Significant at a $5 \%$ level.

*** Significant at a $1 \%$ level.

\footnotetext{
${ }^{1}$ The number of lags used in the estimated equations was determined according to the method suggested by Said and Dickey (1984), which means starting with $\mathrm{T}^{1 / 3}$ lags and using sequential t-tests to exclude the last lag if insignificant.

${ }^{2}$ The number of truncation lags used in the Bartlett kernel was determined as suggested by NeweyWest. For this sample size Newey-West suggested 3.
} 